Bài báo khoa hoc

\title{
Đánh giá hiện trạng chất lượng nước mặt và hiệu quả mô hình canh tác lúa nếp ba vụ ở Bắc Vàm Nao, An Giang
}

\author{
Huỳnh Vương Thu Minh ${ }^{*}$, Nguyễn Thành Tâm², Đái Thị Huỳnh Như ${ }^{1}$, Nguyễn \\ Trường Thành ${ }^{1}$, Trần $V a ̆ n ~ T \mathbf{y}^{3}$
}

${ }^{1}$ Khoa Môi trường \& Tài nguyên thiên nhiên, Trường Đại học Cần Thơ; hvtminh@ctu.edu.vn; ntthanh@ctu.edu.vn

${ }^{2}$ Viện Nghiên cứu Phát triển Đồng bằng sông Cửu Long, Trường Đại học Cần Thơ; ngttam@ctu.edu.vn

${ }^{3}$ Khoa Công nghệ, Trường Đại học Cần Thơ; tvty@ctu.edu.vn

*Tác giả liên hệ: hvtminh@ctu.edu.vn; Tel.: +84-939610020

Ban Biên tập nhận bài: 6/8/2021; Ngày phản biện xong: 17/9/2021; Ngày đăng bài: $25 / 12 / 2021$

Tóm tắt: Đánh giá chất lượng nước mặt và hiệu quả mô hình canh tác lúa nếp ba vụ được thực hiện trong vùng đê bao khép kín Bắc Vàm Nao (BVN), tỉnh An Giang. Các chỉ tiêu chất lượng nước mặt được thu thập từ Sở Tài nguyên và Môi trường (TN\&MT), gồm: $\mathrm{pH}$, Oxy hòa tan (DO), tổng chất rắn lơ lửng (TSS), nhu cầu oxy sinh học (BOD), nhu cầu oxy hóa học $(\mathrm{COD})$, nitrate $\left(\mathrm{NO}_{3}{ }^{-}\right)$, và phosphorus $\left(\mathrm{PO}_{4}{ }^{3-}\right)$, giai đoạn 2010-2020. Nghiên cứu sử dụng phương pháp đo tại chỗ với các chỉ tiêu: $\mathrm{pH}$, TDS, EC, và DO tại 20 vị trí trong vụ Thu Đông năm 2020. Hiệu quả mô hình canh tác lúa nếp được đánh giá từ phỏng vấn nông hộ. Kết quả cho thấy, $\mathrm{BOD}_{5}$ và $\mathrm{COD}$ trong vùng $\mathrm{BVN}$ cao hơn ở mức ý nghĩa $1 \%$ so với trên sông chính. Tuy nhiên, ảnh hưởng của mô hình thâm canh lúa nếp ở $\mathrm{BVN}$ đến thay đổi chất lượng nước trên sông chính chưa tìm thấy. Chất lượng nước ở đầu mùa vụ Thu Đông tốt hơn ở mức ý nghĩa $1 \%$ so với giữa mùa vụ. Thâm canh mang lại nhiều lợi nhuận; tuy nhiên, lợi nhuận bị ảnh hưởng phần lớn bởi năng suất, giá bán và chi phí đầu tư. Những năm gần đây, năng suất lúa nếp bị giảm, lợi nhuận thấp hơn và ô nhiễm môi trường nước nhiều hơn so với trước đây.

Từ khóa: Chất lượng nước nội đồng; Năng suất lúa; Lợi nhuận; Đê bao khép kín; Phú Tân.

\section{Mở đầu}

Nông nghiệp vừa là nguồn gây ô nhiễm cũng là đối tượng chịu ảnh hưởng từ ô nhiễm nguồn nước. Nguồn thải từ nông nghiệp thường bị tác động bởi đặc tính thủy văn và khó quản lý hơn nguồn thải tập trung. Hơn nữa, ngành nông nghiệp là đơn vị sử dụng tài nguyên nước lớn nhất trên toàn cầu. Lượng nước cấp cho nông nghiệp ước tính xấp xỉ $70 \%$ tồng nguồn nước cấp cho các đối tượng sử dụng nước [1]. Các đồng bằng rộng lớn ở Châu Á, lúa là cây lương thực chính và được trồng ở khắp nơi với nhiều mô hình canh tác khác nhau. Rủi ro ảnh hưởng của dư lượng thuốc bảo vệ thực vật từ sản xuất lúa đến nguồn lợi thủy sản trên sông hay ảnh hưởng đến sức khỏe con người. Do đó, cần thiết có cái nhìn tổng quát về ô nhiễm nguồn nước từ các mô hình trồng lúa nhằm định hướng lựa chọn mô hình sản xuất ít ảnh hưởng đến môi trường nước. 
Đồng bằng sông Cửu Long (ĐBSCL) cũng như các đồng bằng rộng lớn ở khu vực Châu Á (Ganges-Brahmaputra ở Bangladesh, Ayeyarwady ở Myanmar) là những vùng trồng lúa chính và có vai trò quan trọng đối với an ninh lương thực và sinh kế cho người dân trong khu vực [1]. Năng suất và sản lượng lúa được ghi nhận ở tỉnh An Giang cao hơn so với các tỉnh khác trong khu vực ĐBSCL. An Giang có vị thế thuận lợi nằm giữa hai sông chính thuộc hệ thống sông Mê Công nhận được nhiều nguồn nước và lượng phù sa. Tuy nhiên, An Giang chịu ảnh hưởng lũ từ tháng 8 đến tháng 11 hàng năm. Từ trước năm 1996, người dân An Giang trồng hai vụ lúa là chính, gồm vụ Đông Xuân và Hè Thu. Mô hình này được triển khai trong vùng được bảo vệ bởi hệ thống đê bao tháng Tám (hay còn gọi là đê bao lửng). Từ sau năm 1996, An Giang tiếp tục xây dựng thêm hệ thống đê bao khép kín mới và đồng thời chuyển từ đê bao tháng Tám sang đê bao khép kín nhằm mở rộng diện tích canh tác lúa vụ ba (vụ Thu Đông) [2-4]. Nhiều nghiên cứu cho thấy canh tác lúa ba vụ, trong năm năm đầu lợi nhuận có tăng, tuy nhiên những năm về sau thì lợi nhuận giảm và các nghiên cứu cũng tiết lộ thêm rằng hiệu quả của mô hình độc canh cây lúa kém hơn so với các mô hình luân canh [5-6]. Mô hình luân canh lúa-màu có thể cải thiện độ phì nhiêu đất so với mô hình lúa ba vụ vì tập quán sử dụng phân hóa học thay vì sử dụng bón phân hữu cơ; tuy nhiên, mô hình luân canh ít được áp dụng rộng rãi với quy mô lớn [5-6]. Từ những nghiên cứu trước đây cho thấy rằng, mặc dù trong những năm gần đây, một vài hộ nông dân ở ĐBSCL đã chuyển đổi mô hình sản xuất lúa độc canh sang mô hình sản xuất luân canh: lúa-màu, lúa-màu-màu, hay lúa-cá nhằm tăng lợi nhuận; tuy nhiên, do các mô hình này cần nhiều công lao động và kỹ thuật canh tác có trình độ tay nghề cao cũng như giá sản phẩm bị chi phối nhiều bởi biến động thị trường [5-6]. Vì vậy, hiệu quả sản xuất của mô hình luân canh còn thấp ở quy mô nhỏ lẻ và ở quy mô hộ nông dân với khả năng tài chính thấp [6-8]. Hệ thống canh tác luân canh chỉ áp dụng có hiệu quả ở những hộ có điều kiện kinh tế tốt, có nhiều lao động, chủ động nguồn nước và kinh nghiệm và quy mô canh tác lớn [6-9]. Ngoài ra, [8] cũng chỉ ra trình độ chủ hộ và người lao động có ảnh hưởng đến hiệu quả kinh tế của mô hình luân canh.

Ở ĐBSCL, hệ thống kiểm soát lũ BVN được đề xuất xây dựng từ năm 1985 và triển khai tại huyện Phú Tân và một phần thuộc Thị xã Tân Châu, An Giang. Trong giai đoạn 1996 và 2017, sản lượng lúa ở các huyện tại An Giang tăng lên khi các diện tích đê bao khép kín được mở rộng (Hình 1). Tuy nhiên, đê bao đã hạn chế lượng phù sa tích lũy cho ruộng lúa cũng như giảm lượng nước trao đổi giữa đồng ruộng và môi trường bên ngoài. Bên cạnh đó, để duy trì năng suất lúa, một lượng lớn phân bón được sử dụng đã làm tăng ô nhiễm nước mặt trong kênh nội đồng [3]. Những nghiên cứu trước đây tại $\mathrm{BVN}$ hay trong vùng đê bao khép kín, phần chính chỉ xem xét một vài khía cạnh như là đánh giá hiệu quả vận hành và quản lý hệ thống thủy lợi hay so sánh các mô hình canh tác về mặt lợi nhuận, kỹ thuật và yếu tố con người; so sánh chất lượng nước mặt ở vùng đê bao khép kín với vùng đê bao tháng 8 và vùng ngoài đê bao ở An Giang [3, 4, 10-12]. Nghiên cứu [3] cho thấy các chỉ tiêu $\mathrm{COD}, \mathrm{NH}_{4}{ }^{+}, \mathrm{NO}_{2}{ }^{-}$, và $\mathrm{NO}_{3}{ }^{-}$cao trong các kênh rạch cấp 2 ở vùng đê bao khép kín ở An Giang. Tuy nhiên, chi phí lợi nhuận và tác động của các mô hình canh tác đến yếu tố môi trường nước về mặt định tính hoặc định lượng chưa được xem xét đồng thời. Mục tiêu của nghiên cứu này nhằm đánh giá hiện trạng chất lượng nước mặt và hiệu quả mô hình canh tác lúa ba vụ trong vùng đê bao khép kín BVN, An Giang.

\section{Phương pháp nghiên cứu}

\subsection{Khu vưc nghiên cứu}

Phú Tân, nằm trong vùng đê bao khép kín BVN, là một trong bốn huyện cù lao thuộc tỉnh An Giang (Hình 1a). Huyện Phú Tân có diện tích tự nhiên 313,5 km², trong đó 92\% diện tích tự nhiên là trồng lúa nếp [13]. Khu vực BVN có vị trí ở giữa sông Mê Công (tên gọi sông Tiền ở Việt Nam) và sông Bassac (tên gọi sông Hậu ở Việt Nam), cao trình mặt 
đất trung bình từ $1,3 \mathrm{~m}$ đến $3,0 \mathrm{~m}$. Phú Tân là một trong các vùng có thế mạnh về nông nghiệp và thủy sản. Tuy nhiên, Phú Tân cũng tiếp nhận nhiều nước thải từ hoạt động nông nghiệp (trồng lúa và chăn nuôi) thuộc vùng nội địa của ĐBSCL. Trạm quan trắc tại Châu Đốc có lượng mưa khá thấp, trung bình nhiều năm xấp xỉ $1.031 \mathrm{~mm}$ (giai đoạn từ 1978 đến 2020) (Hình 1b). Ảnh hưởng từ gió mùa Tây Nam, mùa mưa thường xuất hiện từ tháng 5 đến tháng 11 , nhiệt độ không khí thấp nhất và cao nhất xuất hiện lần lượt vào tháng 1 và tháng 4 . Nhiều nghiên cứu cho thấy chất lượng nước trong vùng nghiên cứu bị ô nhiễm vào mùa mưa có thể tăng, do nguồn nước đến vùng nghiên cứu đã bị ô nhiễm và cùng với sự cuốn trôi chất ô nhiễm trong đất theo dòng chảy tràn [3-4].
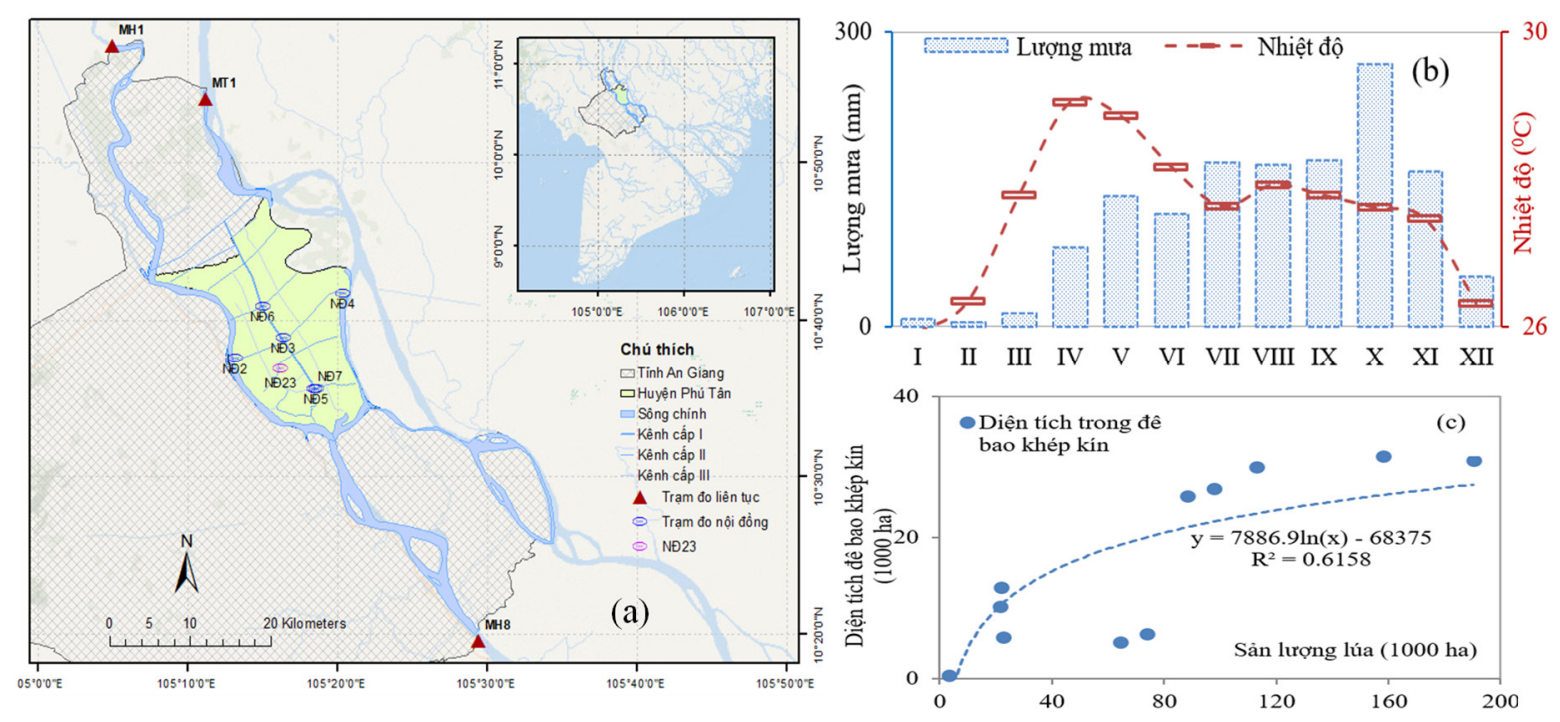

Hình 1. Vị trí các điểm quan trắc tự động trên sông chính và các điểm nội đồng ở huyện Phú Tân, Bắc Vàm Nao, An Giang (a). Diễn biến nhiệt độ và lượng mưa trung bình nhiều năm tại trạm Châu Đốc (An Giang), 1978-2018 (b). Tương quan giữa sản lượng lúa trung bình và diện tích đê bao khép kín ở các huyện tại An Giang, 1996-2017 (c). Số liệu diện tích đê bao được thu thập từ sở Nông nghiệp và Phát triển Nông thôn An Giang, số liệu sản lượng lúa được thu thập từ niên giám thông kê tỉnh An Giang.

\section{2. Đánh giá hiện trạng chất luợng nước mặt}

Nghiên cứu thu thập số liệu chất lượng nước bao gồm: $\mathrm{pH}, \mathrm{DO}, \mathrm{TSS}, \mathrm{BOD}_{5}, \mathrm{COD}$, $\mathrm{NO}_{3}{ }^{-}$, và $\mathrm{PO}_{4}{ }^{3-}$ (cho 6 vị trí quan trắc từ năm 2010 đến 2014 và cho 01 vị trí quan trắc từ năm 2015 đến 2020). Hệ thống quan trắc của vùng nghiên cứu có thay đổi, do đó nghiên cứu phân tích tương quan giữa các chỉ tiêu chất lượng nước trong giai đoạn 2010-2014, so sánh chất lượng nước giữa trong đê bao khép kín với các trạm đo trên sông chính trong giai đoạn 2015/2016-2020. Số liệu quan trắc được thu thập từ sở TN\&MT An Giang, định kỳ 3 lần/năm (tháng 3, 6 và 9), tại các vị trí tương ứng: Nội đồng 2 (ký hiệu NĐ2), NĐ3, NĐ4, NĐ5, NĐ6 và NĐ7 (Hình 1a) giai đoạn 2010-2024 và tại 1 vị trí NĐ23 (tại Rạch Mương Khai), giai đoạn 2015-2020. Các chỉ tiêu quan trắc chất lượng nước mặt gồm: pH, DO, $\mathrm{TSS}, \mathrm{BOD}_{5}, \mathrm{COD}, \mathrm{NO}_{3}{ }^{-}$và $\mathrm{PO}_{4}{ }^{3-}$.

Bên cạnh đó nghiên cứu sử dụng máy AQUA TROLL 400 đo tại chỗ (in-situ) gồm các chỉ tiêu: $\mathrm{pH}, \mathrm{TDS}, \mathrm{EC}$ và $\mathrm{DO}$ tại 20 vị trí trong vùng đê bao khép kín $\mathrm{BVN}$ vào năm 2020 (Hình $2 \mathrm{a}, 2 \mathrm{~b}$ ) tại hai thời điểm trong thời gian sinh trưởng của cây lúa. Ngoài ra, nghiên cứu thu thập số liệu chất lượng của nước mặt được quan trắc liên tục (số liệu ngày) tại 3 vị trí trên sông chính (MT1 ở đầu sông Tiền thuộc xã Vĩnh Xương, MH1 ở đầu nguồn sông Hậu thuộc thị trấn Long Bình và MH8 ở cuối sông Hậu tại thành phố Long Xuyên, đoạn giáp thành phố Cần Thơ từ năm 2016 đến 2020 nhằm làm cơ sở so sánh giữa chất lượng nước trong vùng nghiên cứu. Phương pháp thống kê mô tả, phân tích tương quan, và kiểm 
định $\mathrm{T}$ được sử dụng nhằm đánh giá biến động chất lượng nước trong một ngày và trong thời gian sinh trưởng của cây lúa nếp.

\section{3. Đánh giá hiệu quả mô hình canh tác lúa nếp ba vu trong vùng đê bao khép kín}

Hiệu quả mô hình canh tác lúa nếp ba vụ trong vùng đê bao khép kín $\mathrm{BVN}$ được đánh giá thông qua phỏng vấn nông hộ trong khu vực nghiên cứu (Hình 2c). Ngoài ra, nghiên cứu tiến hành khảo sát và phỏng vấn 52 hộ dân trồng lúa nếp tại vùng đê bao khép kín $\mathrm{BVN}$ và chọn mẫu theo phương pháp chọn mẫu ngẫu nhiên thuận tiện. Nội dung phỏng vấn tập trung vào các thông tin: (i) năng suất lúa các vụ; (ii) giá bán lúa nếp năm 2020; (iii) thực trạng thu chi của mô hình trồng lúa nếp (tổng thu, tổng chi và lợi nhuận); và (iv) thông tin về sự thay đổi năng suất, lợi nhuận, môi trường hiện nay so với trước đây.
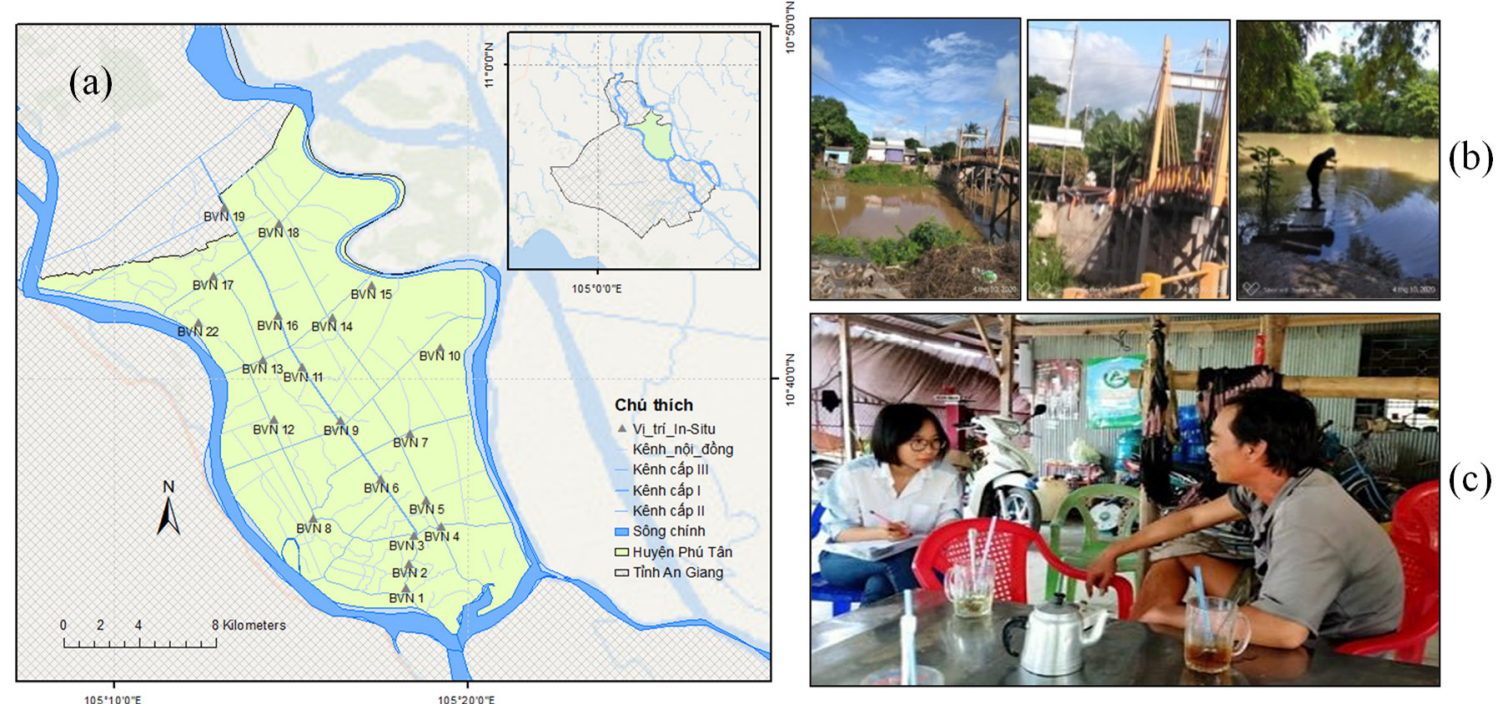

Hình 2. (a) Vị trí khảo sát chất lượng nước nước mặt; (b) Hình ảnh đo tại chổ (In-Situ) chất lượng nước; và (c) Phỏng vấn nông hộ tại huyện Phú Tân, BVN.

\section{Kết quả và thảo luận}

\subsection{Chất lượng nước tại ba vị trí trên sông chính, giai đoạn 2016-2020}

Diễn biến $\mathrm{BOD}_{5}, \mathrm{COD}$, và $\mathrm{DO}$ tại vị trí $\mathrm{MT} 1$ trên sông Tiền, và hai vị trí $(\mathrm{MH} 1$ trên $\mathrm{BVN}, \mathrm{MH} 8$ dưới $\mathrm{BVN}$ ) trên sông Hậu được thể hiện trong Hình 3 và Bảng 1 . Hàm lượng oxy hòa tan dao động từ 2,11 (nhỏ nhất) đến 9,07 (lớn nhất), trong đó, giá trị $\mathrm{DO}$ trung bình từ 5,15-5,44 tại các trạm đo, đạt quy chuẩn QCVN 08-MT:2015/BTNMT cột A2 [14]. Điều này cho thấy hàm lượng oxy hòa tan trong nước vẫn đảm bảo cho các thủy sinh vật.

Giá trị $\mathrm{BOD}_{5}$ và $\mathrm{COD}$ có hệ số biến động gần như nhau và khá lớn (sau chỉ tiêu TSS) so với các chỉ tiêu khác khi quan trắc đồng thời. Tại các trạm đo, giá trị $\mathrm{BOD}_{5}$ nhỏ nhất từ 4-5 mg/l (đạt quy chuẩn cột $\mathrm{A} 1$ ), giá trị cao nhất từ 19-21 mg/l (đạt quy chuẩn cột $\mathrm{B} 2$ ), trung bình từ 8,70-9,02 mg/1 (đạt quy chuẩn cột $\mathrm{B} 1$ ). Tương tự, giá trị $\mathrm{COD}$ có thời điểm đạt quy chuẩn cột $\mathrm{A} 1$ (giá trị nhỏ nhất), có thời điểm đạt quy chuẩn cột $\mathrm{B} 1$ (giá trị lớn nhất), giá trị trung bình đạt quy chuẩn cột $\mathrm{A} 2$. Tỷ số $\mathrm{BOD}_{5} / \mathrm{COD}$ của các trạm đo ở thời điểm giá trị lớn nhất khoảng 0,66 , thời điểm giá trị nhỏ nhất từ $0,57-0,63$ và tỷ số trung bình khoảng 0,65 . Từ các kết quả này cho thấy, hàm lượng các hợp chất hữu cơ (thông qua chỉ tiêu $\mathrm{BOD}_{5}$ và $\mathrm{COD}$ ) gây ô nhiễm không đáng kể (đạt quy chuẩn từ $\mathrm{B} 1-\mathrm{A} 2$ ) và đa số là ở dạng hòa tan, dễ phân hủy (tỷ số $\mathrm{BOD}_{5} / \mathrm{COD}$ trung bình 0,65 ).

Hình 4 thể hiện diễn biến $\mathrm{pH}$ và TSS trong giai đoạn 2016-2020. Trong đó, giá trị pH đa số đạt quy chuẩn cột $\mathrm{A} 2-\mathrm{A} 1$ (trạm $\mathrm{MT} 1$ và $\mathrm{MH} 8$ ), riêng trạm $\mathrm{MH1}$, trong hai năm 2016-2017 giá trị pH đa số đạt quy chuẩn cột $\mathrm{B} 1$, các năm trở về sau, đa số giá trị pH đạt quy chuẩn từ $\mathrm{A} 2$ đến $\mathrm{A} 1$. Nhìn chung, $\mathrm{pH}$ trung bình ở 3 vị trí đều nằm trong giới hạn cho 
phép, dao động từ 6,5-7,5 các giá trị này ở khoảng trung tính và tối thích của đa số thủy sinh vật. Ngược lại, giá trị TSS trung bình chỉ đạt quy chuẩn cho phép cột B1 và có mức độ biến động lớn nhất so với các chỉ số chất lượng khác tại cả 3 trạm. Tuy nhiên, các giá trị TSS này vẫn có thể dùng cho mục đích tưới tiêu, thủy lợi (cột $\mathrm{B} 1$, QCVN 08MT:2015/BTNMT-quy định). Từ kết quả kiểm định $\mathrm{T}$ cho thấy, không có sự khác biệt có ý nghĩa về $\mathrm{BOD}_{5}, \mathrm{COD}$, và TSS ở vị trí đầu $\mathrm{BVN}(\mathrm{MH} 1)$ và vị trí cuối $\mathrm{BVN}(\mathrm{MH})$ cũng như các phân tích ở trên cho thấy chưa tìm thấy sự ảnh hưởng có ý nghĩa từ hoạt động sản xuất nông nghiệp ở BVN đến chất lượng nước trên sông Hậu.

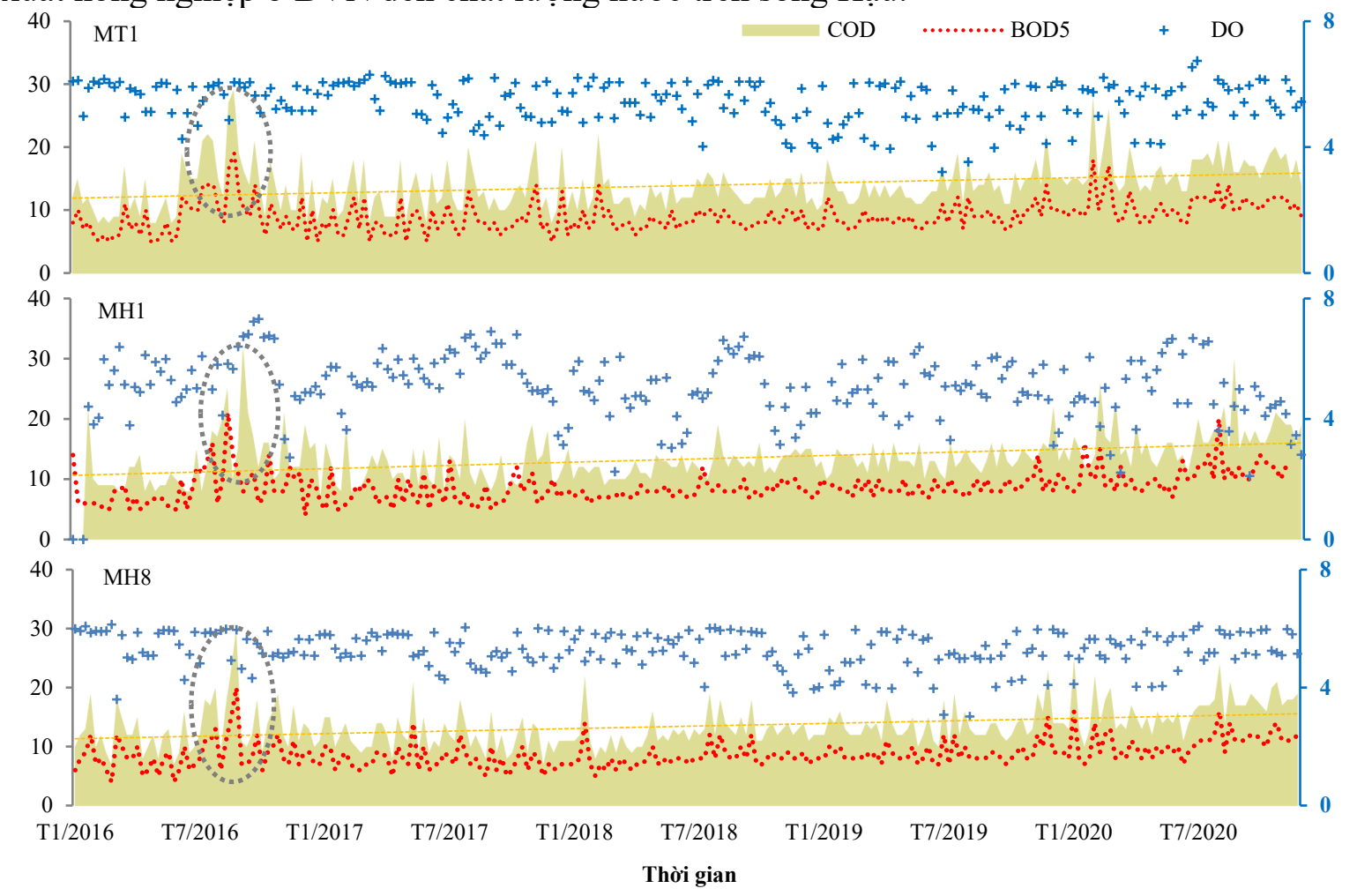

Hình 3. Diễn biến chất lượng nước $\left(\mathrm{BOD}_{5}, \mathrm{COD}\right.$ và $\left.\mathrm{DO}\right)$ tại vị trí $\mathrm{MT1}$ 1, $\mathrm{MH} 1$ và $\mathrm{MH} 8$. Trục tọa độ bên trái thể hiện giá trị $\mathrm{BOD}_{5}$ và $\mathrm{COD}$, trục tọa độ bên phải thể hiện giá trị $\mathrm{DO}$.

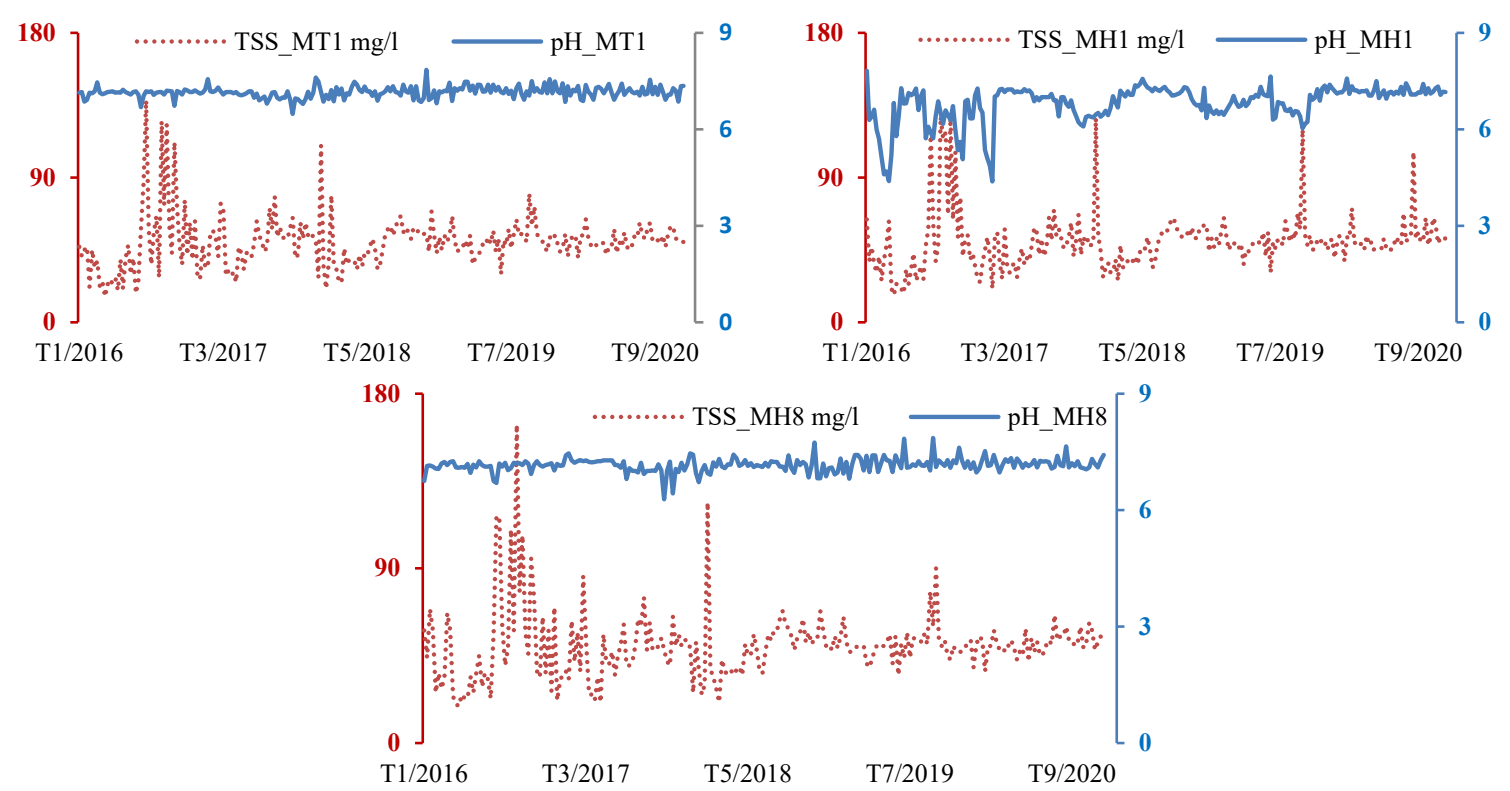

Hình 4. Diễn biến chất lượng nước TSS và pH tại vị trí MT1, MH1 và MH8. Trục tọa độ bên trái thể hiện giá trị TSS, trục tọa độ bên phải thể hiện giá trị pH. 
Bảng 1. Các đặc trưng chất lượng nước tại 3 trạm trên sông Tiền và Hậu, giai đoạn 2016-2020.

\begin{tabular}{|c|c|c|c|c|c|c|c|c|c|c|c|c|c|c|}
\hline \multirow{2}{*}{ Chỉ số } & \multirow{2}{*}{$\begin{array}{c}\text { Đo'n } \\
\text { vị }\end{array}$} & \multirow{2}{*}{$\begin{array}{c}\text { QCVN 08- } \\
\text { MT:2015/BTNMT } \\
\text { cột A1 }\end{array}$} & \multicolumn{3}{|c|}{ Lớn nhất } & \multicolumn{3}{|c|}{ Nhỏ nhất } & \multicolumn{3}{|c|}{ Trung bình } & \multicolumn{3}{|c|}{ Hệ số biến động, Cv } \\
\hline & & & MT1 & MH1 & MH8 & MT1 & MH1 & MH8 & MT1 & MH1 & MH8 & MT1 & MH1 & MH8 \\
\hline $\mathrm{BOD}_{5}$ & $\mathrm{mg} / 1$ & 4 & 19,00 & 21,00 & 20,00 & 5,00 & 4,00 & 4,00 & 9,02 & 8,70 & 8,73 & 0,27 & 0,29 & 0,26 \\
\hline COD & $\mathrm{mg} / \mathrm{l}$ & 10 & 29,00 & 32,00 & 30,00 & 8,00 & 7,00 & 7,00 & 13,89 & 13,46 & 13,44 & 0,27 & 0,28 & 0,26 \\
\hline BOD5/COD & - & - & 0,66 & 0,66 & 0,67 & 0,63 & 0,57 & 0,57 & 0,65 & 0,65 & 0,65 & - & - & - \\
\hline $\mathrm{pH}$ & - & $6-8,5$ & 7,85 & 7,82 & 7,86 & 6,48 & 4,38 & 6,28 & 7,15 & 6,80 & 7,16 & 0,03 & 0,09 & 0,03 \\
\hline TSS & $\mathrm{mg} / 1$ & 20 & 138,00 & 128,00 & 164,00 & 16,00 & 17,00 & 19,00 & 49,78 & 49,94 & 50,11 & 0,33 & 0,35 & 0,35 \\
\hline
\end{tabular}

\section{2. Đặc tính chất luợng nước trong vùng đê bao khép kín}

Bảng 2 thể hiện kết quả phân tích tương quan giữa các chỉ tiêu chất lượng nước trong vùng BVN, giai đoạn 2010-2014. Nhiệt độ nước và chỉ số TSS có liên quan đến các đợt lấy mẫu nước khác nhau trong năm (tháng 3 , tháng 6 và tháng 9). Trong đó, nhiệt độ có xu hướng giảm theo thời gian lấy mẫu nước trong năm với hệ số tương quan âm $(\mathrm{r}=-0,288)$. Tuy nhiên, chỉ số TSS lại có tương quan dương với số đợt lấy mẫu nước trong năm, nghĩa là chỉ số này có xu hướng tăng vào tháng 6 và tháng 9 . Trong giai đoạn $2010-2014, \mathrm{pH}$ có tương quan đồng biến với nồng độ $\mathrm{PO}_{4}^{3-}(\mathrm{r}=0,392)$; DO có tương quan nghịch biến với nhiệt độ nước $(\mathrm{r}=-0,314)$ và tương quan đồng biến với TSS $(\mathrm{r}=0,442)$.

Giai đoạn từ 2015 đến 2020, trong vùng đê bao khép kín $\mathrm{BVN}$ chỉ quan trắc ở vị trí $\mathrm{NĐ23,} \mathrm{các} \mathrm{chỉ} \mathrm{tiêu} \mathrm{chất} \mathrm{lượng} \mathrm{nước} \mathrm{gồm:} \mathrm{TSS,} \mathrm{BOD}_{5}, \mathrm{COD}, \mathrm{pH}, \mathrm{DO}, \mathrm{PO}_{4}{ }^{3-}$ và $\mathrm{NO}_{3}{ }^{-}$(Hình 5). Chỉ số pH trung bình trong giới hạn cho phép (đạt quy chuẩn cột $\mathrm{A} 2-\mathrm{A} 1$ ), trong khi $\mathrm{DO}$ trung bình thấp, đạt cột B2 của QCVN 08-MT:2015/BTNMT. Mặc dù TSS trung bình cao hơn $13,5 \%$ so với ba trạm trên sông chính (Bảng 1). Tuy nhiên, qua kiểm định $\mathrm{T}$ cho thấy, TSS tại BVN và trên sông chính có sự khác biệt không ý nghĩa ở mức ý nghĩa $5 \%$. Tương tự, $\mathrm{BOD}_{5}$ và $\mathrm{COD}$ trung bình cao hơn lần lượt là $30,2 \%$ và $30,3 \%$ và biến động cao hơn lần lượt là $35 \%$ và $37 \%$ so với $M T 1, M H 1$ và $M H 8$. Qua kiểm định $T$ cho thấy, $\mathrm{BOD}_{5}$ và $\mathrm{COD}$ tại $\mathrm{BVN}$ và ngoài sông chính khác bi nơcó ý nghĩa về mặt độ lớn $(\mathrm{p} \leq 0,01)$. Tuy nhiên, $\mathrm{BOD}_{5}$ trung bình tại $\mathrm{BVN}$ và trên sông chính đều đạt cột $\mathrm{B} 1$, trong khi $\mathrm{COD}$ tại $\mathrm{BVN}$ đạt cột $\mathrm{B} 1$ thì $\mathrm{COD}$ trên sông chính đạt cột $\mathrm{A} 2$. Ngoài ra, tỷ số trung bình giữa $\mathrm{BOD}_{5} / \mathrm{COD}$ xấp xỉ 0,65 , kết quả này cũng cho thấy hợp chất hữu cơ trong vùng $\mathrm{BVN}$ phần lớn thuộc dạng ô nhiễm có nguồn gốc sinh học và dễ phân hủy như ngoài sông chính. Mặt khác, hệ số tương quan giữa nitrate và phosphate khá thấp (Hình 5), nitrate có xu thế tăng và phosphate có xu thế giảm. Chỉ số nitrate và phosphate trung bình đều đạt cột $\mathrm{A} 2$ của quy chuẩn.

Bảng 2. phân tích mối tương quan giữa các chỉ tiêu chất lượng nước trong vùng đê bao khép kín (2010-2014).

\begin{tabular}{|c|c|c|c|c|c|c|c|c|c|}
\hline \multicolumn{2}{|c|}{ Chỉ tiêu/phương pháp thử } & \multirow{2}{*}{$\frac{\text { Đọtt }}{-.288^{*}}$} & \multirow{2}{*}{$\begin{array}{r}\text { Nhiệt độ } \\
1\end{array}$} & \multirow[t]{2}{*}{ pH } & \multirow[t]{2}{*}{ DO } & \multirow[t]{2}{*}{ TSS } & \multirow[t]{2}{*}{ BOD $_{5}$} & \multirow[t]{2}{*}{$\mathrm{NO}_{3}^{-}$} & \multirow[t]{2}{*}{$\mathrm{PO}_{4}{ }^{3-}$} \\
\hline Nhiệt độ & $\begin{array}{l}\text { Pearson Correlation } \\
\text { Sig. (2-tailed) }\end{array}$ & & & & & & & & \\
\hline $\mathrm{pH}$ & Pearson Correlation & -.073 & -.139 & 1 & & & & & \\
\hline & Sig. (2-tailed) & .544 & .246 & & & & & & \\
\hline DO & $\begin{array}{l}\text { Pearson Correlation } \\
\text { Sig. (2-tailed) }\end{array}$ & $\begin{array}{r}.337 * * \\
.004\end{array}$ & $\begin{array}{r}-.314 * * \\
.007\end{array}$ & $\begin{array}{l}.035 \\
.769\end{array}$ & 1 & & & & \\
\hline TSS & $\begin{array}{l}\text { Pearson Correlation } \\
\text { Sig. (2-tailed) }\end{array}$ & $\begin{array}{r}.430 * * \\
.000\end{array}$ & $\begin{array}{r}-.166 \\
.164\end{array}$ & $\begin{array}{r}-.004 \\
.970\end{array}$ & $\begin{array}{r}.442 * * \\
.000\end{array}$ & 1 & & & \\
\hline $\mathrm{BOD}_{5}$ & Pearson Correlation & -.149 & .096 & -.211 & -.213 & -.044 & 1 & & \\
\hline & Sig. (2-tailed) & .213 & .424 & .075 & .073 & .715 & & & \\
\hline $\mathrm{NO}_{3}^{-}$ & $\begin{array}{l}\text { Pearson Correlation } \\
\text { Sig. (2-tailed) }\end{array}$ & $\begin{array}{l}.212 \\
.080\end{array}$ & $\begin{array}{r}-.076 \\
.533\end{array}$ & $\begin{array}{l}.197 \\
.105\end{array}$ & $\begin{array}{l}.191 \\
.115\end{array}$ & $\begin{array}{l}.065 \\
.597\end{array}$ & $\begin{array}{r}-.074 \\
.544\end{array}$ & 1 & \\
\hline $\mathrm{PO}_{4}^{3-}$ & $\begin{array}{l}\text { Pearson Correlation } \\
\text { Sig. (2-tailed) }\end{array}$ & $\begin{array}{r}-.015 \\
.901\end{array}$ & $\begin{array}{r}-.162 \\
.175\end{array}$ & $\begin{array}{r}.392 * * \\
.001\end{array}$ & $\begin{array}{r}-.145 \\
.223\end{array}$ & $\begin{array}{r}-.098 \\
.413\end{array}$ & $\begin{array}{l}.078 \\
.517\end{array}$ & $\begin{array}{l}.234 \\
.053\end{array}$ & 1 \\
\hline
\end{tabular}

Ghi chú: *: có sụ tương quan ở mức ý nghĩa 5\%; **: có sụ tương quan ở mức ý nghĩa 1\%. 


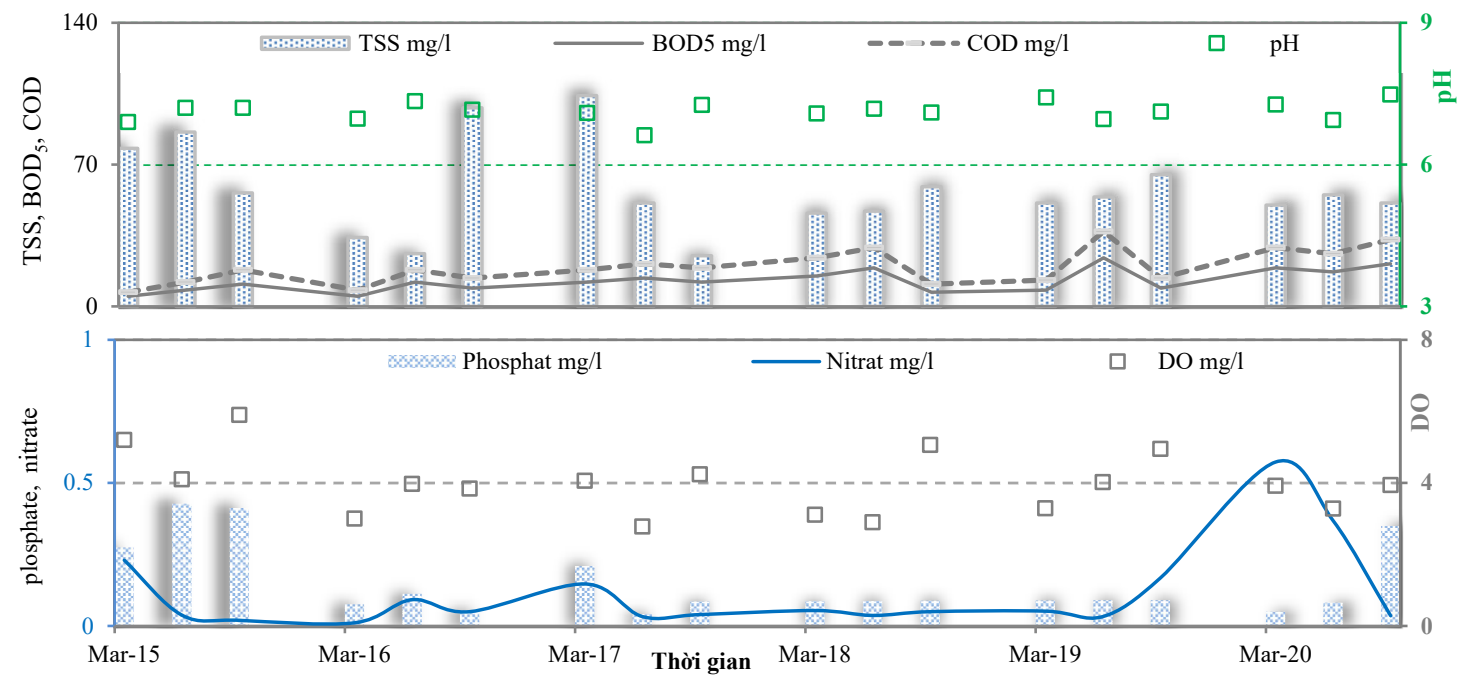

Hình 5. Diễn biến chất lượng nước $\left(\mathrm{BOD}_{5}, \mathrm{COD}, \mathrm{TSS}, \mathrm{pH}, \mathrm{DO}, \mathrm{PO}_{4}{ }^{3-}\right.$ và $\left.\mathrm{NO}_{3}{ }^{-}\right)$tại vị trí $\mathrm{NĐ23}$ trong vùng đê bao khép kín BVN, 2015-2020.

\subsection{Kết quả đánh giá chất lương nuớc tù số liệu so cấp 20 vị trí nội đồng}

Hình 6 cho thấy các chỉ số chất lượng nước ít thay đổi trong ngày, tuy nhiên có sự biến động chỉ số chất lượng nước trong thời điểm đầu vụ và giữa mùa vụ Thu Đông. Chỉ số DO và $\mathrm{pH}$ trung bình được tìm thấy đều trong giới hạn cho phép trong khi TDS, EC cao hơn giới hạn cho phép của quy chuẩn QCVN 08-MT:2015/BTNMT. Kết quả từ kiểm định $\mathrm{T}$ đối với các chỉ tiêu chất lượng nước gồm: $\mathrm{pH}, \mathrm{TDS}, \mathrm{EC}$ và $\mathrm{DO}$ cho thấy vào đầu và giữa mùa vụ Thu Đông có sự khác biệt có ý nghĩa $(\mathrm{p} \leq 0,01)$. Cụ thể: TDS $(39,8 \pm 6,9), \mathrm{EC}(67,3$ $\pm 10,9)$, và $\mathrm{DO}(4,2 \pm 1,2)$ ở đầu mùa vụ thấp hơn giữa mùa vụ $\operatorname{TDS}(80,6 \pm 19,9)$, $\mathrm{EC}$ $(134,9 \pm 33,9)$ và $\mathrm{DO}(4,5 \pm 1,0) ; \mathrm{pH}(8,8 \pm 0,9)$ ở đầu mùa vụ cao hơn $\mathrm{pH}(7,8 \pm 0,7)$ cuối mùa vụ Thu Đông. Một điểm đáng lưu ý, vào các ngày ghi nhận ô nhiễm cao lại có độ biến động lớn. Theo kết quả phỏng vấn nông hộ cho biết do thời gian bón phân và sử dụng thuốc không đồng nhất.

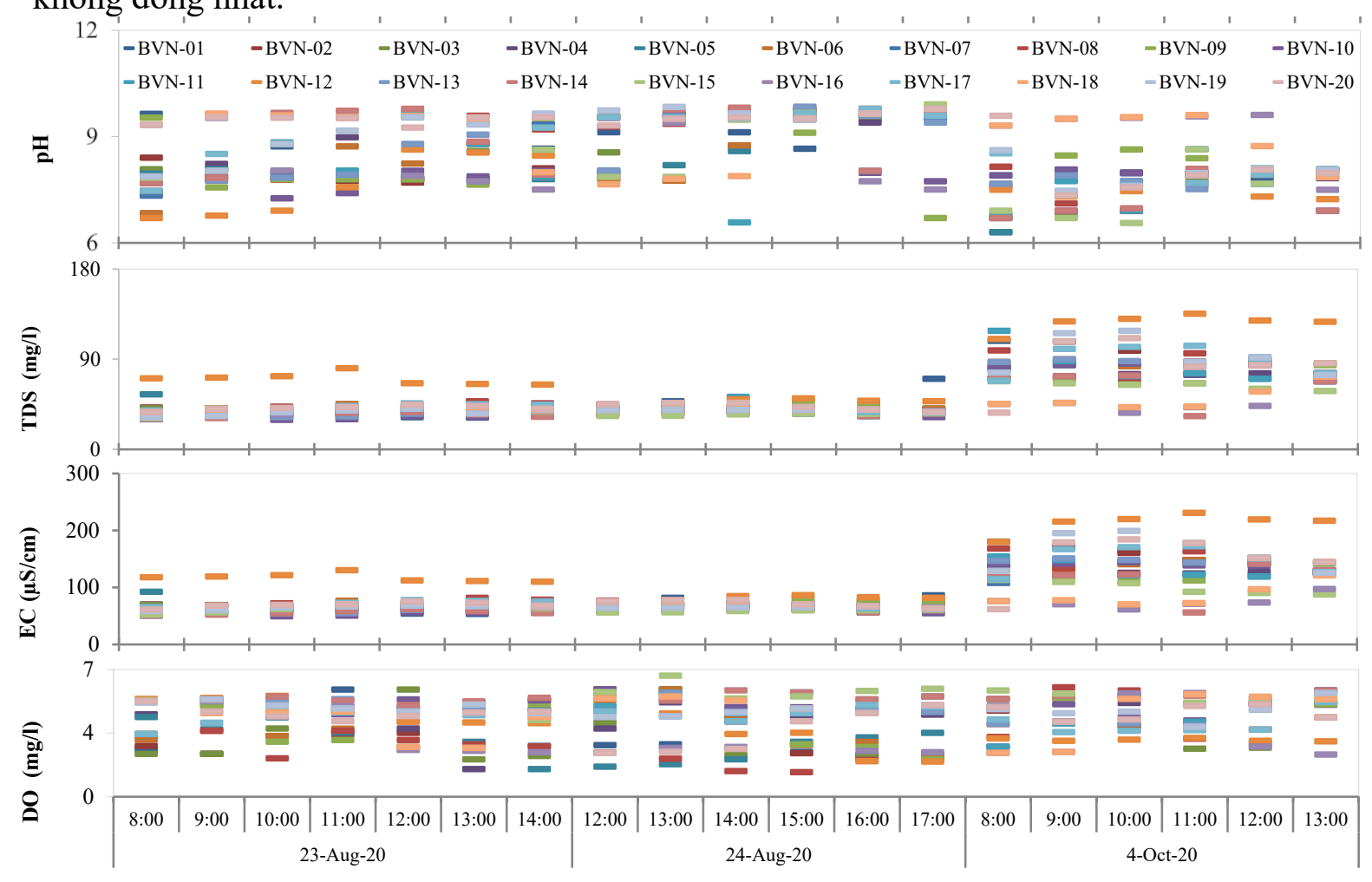

Hình 6. Diễn biến chất lượng nước tại 20 vị trí nội đồng. 


\section{4. Đánh giá hiệu quả mô hình canh tác lúa nếp ba vu trong vùng đê bao khép kín BVN}

Kết quả khảo sát 52 hộ dân trồng lúa nếp tại vùng đê bao khép kín BVN về năng suất và giá bán lúa nếp năm 2020 được thể hiện trên Hình 7 . Năng suất lúa vụ Đông Xuân 2019-2020 cao nhất (7,67 tấn/ha) và năng suất lúa vụ Hè Thu 2020 thấp nhất $(6,18$ tấn/ha). Năng suất lúa có sự khác biệt thống kê ở mức ý nghĩa $1 \%$ giữa ba mùa vụ sản xuất và năng suất lúa trung bình của năm 2020 đạt 6,91 tấn/ha/vụ.

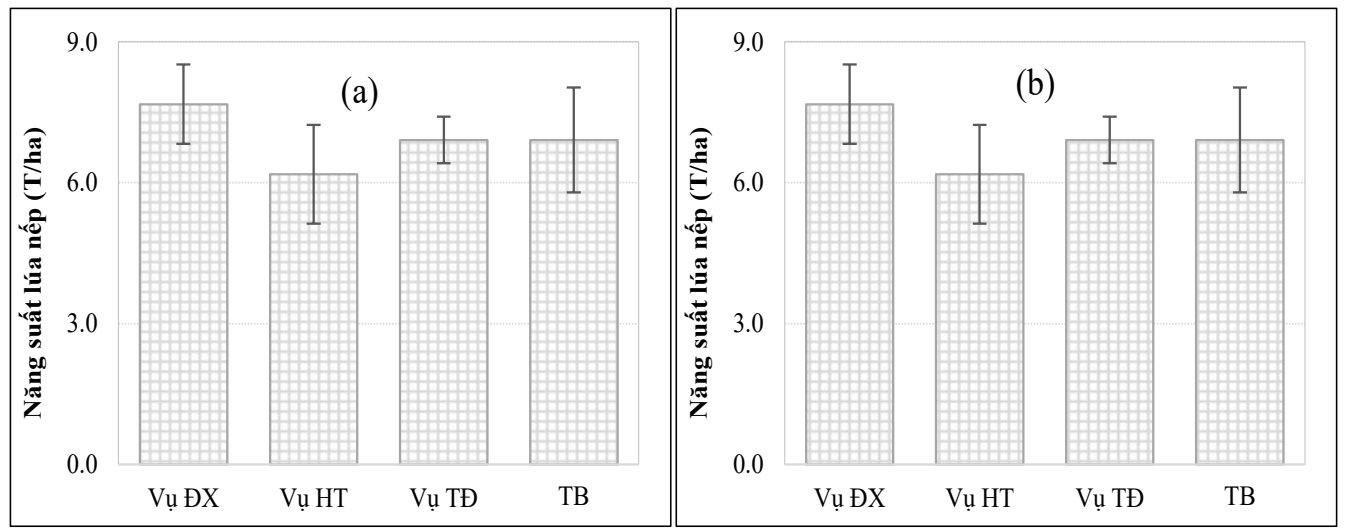

Hình 7. Năng suất và giá bán lúa nếp tại vùng đê bao khép kín năm 2020: (a) Năng suất lúa nếp; (b) Giá bán lúa nếp năm 2020 .

Hình 8 trình bày chi tiết tình hình thu chi của mô hình sản xuất lúa nếp năm 2020 tại vùng $\mathrm{BVN}$. Tổng thu, tổng chi và lợi nhuận của mô hình này có sự khác biệt ý nghĩa ở mức $1 \%$ giữa ba mùa vụ sản xuất. Xét về tổng thu nhập, trung bình mỗi vụ nông dân thu được khoảng 39,5 triệu đồng/ha. Trong đó, nông dân có thu nhập cao nhất ở vụ Thu Đông $(44,7$ triệu đồng/ha) và thấp nhất ở vụ Hè Thu (34,3 triệu đồng/ha). Trung bình mỗi vụ nông dân phải chi ra khoảng 23,5 triệu đồng/ha để đầu tư sản xuất và dao động từ 21,3 triệu đồng/ha (vụ Thu Đông) đến 24,0 triệu đồng/ha (vụ Hè Thu). Qua đó cho thấy, lợi nhuận có sự chênh lệch lớn qua các mùa vụ, trung bình mỗi vụ nông dân có thể đạt được 16,1 triệu đồng/ha lợi nhuận. Tuy nhiên, vụ Hè Thu việc sản xuất của nông dân mang lại lợi nhuận thấp nhất (khoảng 10,3 triệu đồng/ha), trong khi vụ Thu Đông người dân trồng lúa nếp có lợi nhuận cao nhất (khoảng 23,4 triệu đồng/ha). Lợi nhuận sản xuất lúa bị ảnh hưởng rất lớn bởi các yếu tố như năng suất, giá bán và chi phí đầu tư. Trong vụ Đông Xuân 2019-2020, nông dân trồng lúa nếp bị ảnh hưởng của thời tiết trước thu hoạch khoảng 15 ngày bị mưa làm cho lúa bị ngã $100 \%$ nên năng suất lúa bị giảm mạnh, chính vì vậy làm cho năng suất lúa vụ Đông Xuân không cao hơn nhiều so với năng suất lúa vụ Thu Đông, giá bán cũng bị giảm do yếu tố thị trường và chất lượng lúa giảm vì lúa bị đổ ngã và chi phí thu hoạch cũng bị tăng do lúa ngã. Lợi nhuận của vụ Thu Đông cao hơn Đông Xuân phần lớn do sự khác biệt về giá bán lúa vụ Thu Đông rất cao, nhưng năng suất lúa thấp hơn vụ Đông Xuân không nhiều. Ngoài ra, khi xét về hiệu quả đồng vốn trong sản xuất nếp, trung bình nông dân đầu tư 01 đồng tiền vốn cho sản xuất nếp sẽ thu được 0,73 đồng lợi nhuận. Tuy nhiên, có sự khác biệt rất ý nghĩa giữa ba mùa vụ sản xuất, vụ Thu Đông có hiệu quả sản xuất tốt nhất thể hiện qua việc nông dân đầu tư 01 đồng vốn sẽ thu được 1,14 đồng lợi nhuận, kế tiếp là vụ Đông Xuân với hiệu quả đồng vốn là 0,83 và thấp nhất là vụ Hè Thu (HQĐV đạt 0,47$)$.

Kết quả khảo sát người dân về sự thay đổi năng suất, lợi nhuận, môi trường hiện nay so với trước đây cho thấy đa phần hộ dân được khảo sát cho rằng năng suất lúa bị giảm hơn so với trước kia (chiếm 76,9\% tỷ lệ các hộ được khảo sát) (Hình 9). Ngoài ra, kết quả khảo sát về lợi nhuận cho biết lợi nhuận thấp hơn trước đây (chiếm 80,8\%). Kết quả khảo sát về môi trường cho thấy phần lớn hộ dân cho rằng chất lượng môi trường nước xấu hơn trước đây (chiếm 73,1\%), có rất ít hộ dân cho rằng chất lượng môi trường nước hiện tại tốt hơn trước đây (chiếm $1,9 \%$ ), còn lại cho rằng chất lượng môi trường nước không thay đổi (chiếm $25,0 \%)$. 


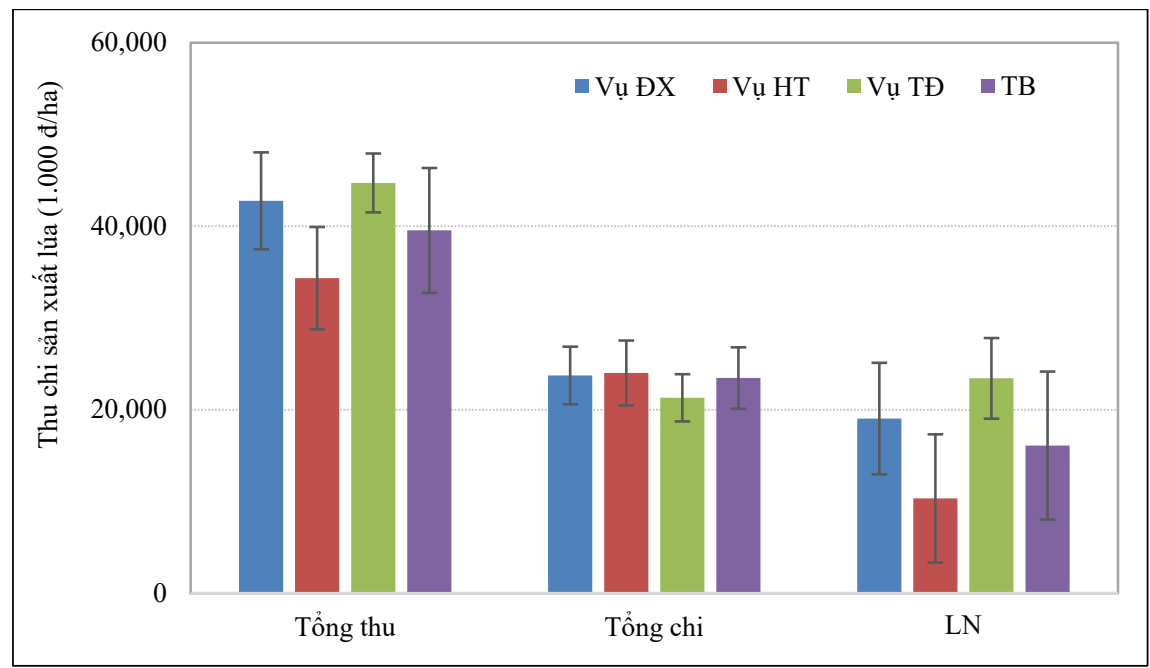

Hình 8. Tình hình thu chi của mô hình sản xuất lúa nếp năm 2020.

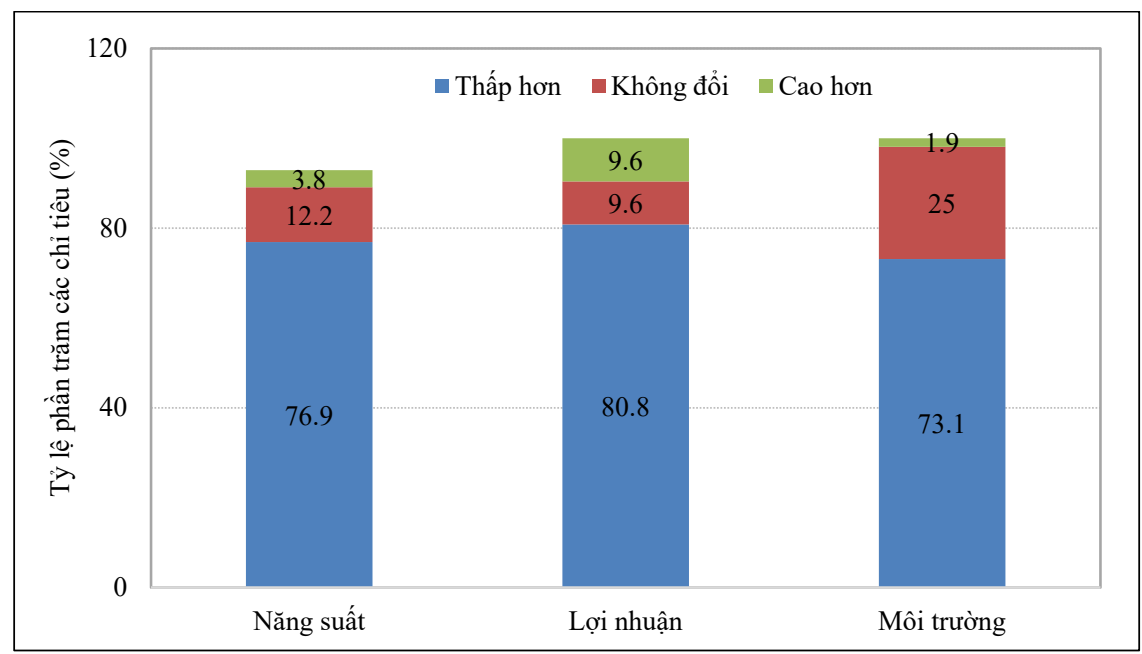

Hình 9. Kết quả khảo sát về sự thay đổi năng suất, lợi nhuận và môi trường.

\section{Kết luận}

Kết quả quan trắc và phân tích chất lượng nước cho thấy, giá trị trung bình của các chỉ tiêu $\left(\mathrm{BOD}_{5}\right.$ và $\left.\mathrm{COD}\right)$ ở vùng đê bao khép kín $\mathrm{BVN}$ khác biệt có ý nghĩa so với trên sông

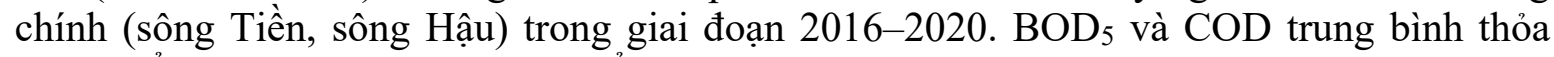
quy chuẩn cột B1-A2 theo quy chuẩn QCVN 08-MT:2015/BTNMT. Giá trị pH và DO của nước trong đê bao khép kín $\mathrm{BVN}$ và trên sông chính nằm trong ngưỡng chịu đựng và đủ đảm bảo cho sự sống của các thủy sinh vật trong nước. Đáng chú ý, tỷ số $\mathrm{BOD}_{5} / \mathrm{COD}$ của nước trong đê bao $\mathrm{BVN}$ và trên sông chính đều xấp xỉ 0,65 . Điều này cho thấy, hàm lượng các hợp chất hữu cơ đa số là ở dạng hòa tan, dễ phân hủy, vẫn có thể dùng cho mục đích tưới tiêu, thủy lợi. Nghiên cứu đã không tìm thấy ảnh hưởng của hoạt động sản xuất nông nghiệp trong vùng đê bao khép kín BVN đến chất lượng nước trên sông chính. Trong vụ Thu Đông, chất lượng nước ở đầu mùa vụ thấp hơn và khác biệt có ý nghĩa thống kê ở mức $1 \%$ so với chất lượng nước ở giữa mùa vụ. Tuy nhiên, cần nghiên cứu thêm cho các mùa vụ khác trong năm cũng như cần đánh giá trong thời gian dài hơn.

Thâm canh trong vùng đê bao khép kín BVN có thể mang lại lợi nhuận cao hơn; tuy nhiên lợi nhuận sản xuất lúa nếp bị ảnh hưởng rất lớn bởi năng suất, giá bán và chi phí đầu tư. Ngoài ra, đa phần các hộ dân cho rằng năng suất lúa nếp bị giảm, lợi nhuận thấp hơn trước đây và chất lượng môi trường nước cũng ô nhiễm hơn. 
Đóng góp của tác giả: Xây dựng ý tưởng nghiên cứu: H.V.T.M., N.T.T., Đ.T.H.N., N.T.T., T.V.T.; Lựa chọn phương pháp nghiên cứu: H.V.T.M., N.T.T., Đ.T.H.N., N.T.T., T.V.T.; Xử lý số liệu: H.V.T.M., N.T.T., Đ.T.H.N.; Lấy mẫu: N.T.T., Đ.T.H.N., N.T.T.; Viết bản thảo bài báo: H.V.T.M., N.T.T., Đ.T.H.N., N.T.T., T.V.T.; Chỉnh sửa bài báo: H.V.T.M., N.T.T., N.T.T., T.V.T.

Lời cảm ơn: Nghiên cứu này thuộc đề tài nghiên cứu khoa học cấp cơ sở thuộc trường Đại học Cần Thơ (MS: T2020-50).

Lời cam đoan: Tập thể tác giả cam đoan bài báo này là công trình nghiên cứu của tập thể tác giả, chưa được công bố ở đâu, không được sao chép từ những nghiên cứu trước đây; không có sự tranh chấp lợi ích trong nhóm tác giả.

\section{Tài liệu tham khảo}

1. Schneider, P.; Asch, F. Rice Production and Food Security in Asian Mega Deltas-A Review on Characteristics, Vulnerabilities and Agricultural Adaptation Options to Cope with Climate Change. J. Agron. Crop Sci. 2020, 206, 491-503.

2. Minh, H.V.T.; Avtar, R.; Mohan, G.; Misra, P.; Kurasaki, M. Monitoring and Mapping of Rice Cropping Pattern in Flooding Area in the Vietnamese Mekong Delta Using Sentinel1A Data: A Case of An Giang Province. ISPRS Int. J. Geo-Inf. 2019, 8, 211. https://doi.org/10.3390/ijgi8050211.

3. Minh, H.V.T.; Kurasaki, M.; Ty, T.V.; Tran, D.Q.; Le, K.N.; Avtar, R.; Rahman, M.; Osaki, M. Effects of Multi-Dike Protection Systems on Surface Water Quality in the Vietnamese Mekong Delta. Water 2019, 11, 1010.

4. Thu Minh, H.V.; Avtar, R.; Kumar, P.; Le, K.N.; Kurasaki, M.; Ty, T.V. Impact of Rice Intensification and Urbanization on Surface Water Quality in An Giang Using a Statistical Approach. Water 2020, 12, 1710. https://doi.org/10.3390/w12061710.

5. Phượng, Đ.T.K.; Xê, Đ.V. So Sánh Hiệu Quả Sản Xuất Giữa Hai Mô Hình Độc Canh Lúa 3 vụ và Lúa Luân Canh Với Màu Tại Huyện Cai Lậy - Tiền Giang. Tạp chi Khoa học Truờng Đại học Cần Tho 2011, 18a, 220-227.

6. Nhựt, Q.M. Phân Tích Lợi Nhuận và Hiệu Quả Theo Quy Mô Sản Xuất Của Mô Hình Độc Canh Ba vụ Lúa và Luân Canh Hai Lúa Một Màu Tại Chợ Mới-An Giang Năm 2005. Tạp chi Khoa học Đại học Cần Tho 2006, 6, 203-212.

7. Đệ, N.V. Giải Pháp Nâng Cao Năng Lực Đội Ngũ Giảng Viên Các Trường Đại Học ở Vùng ĐBSCL Trong Bối Cảnh Hội Nhập. Tạp chí khoa học truờng Đại học Cần Tho 2009, 182192.

8. Thái, L.X. Các Yếu Tố Ảnh Hưởng Đến Thu Nhập Của Nông Hộ Trong Các Mô Hình Sản Xuất Trên Đất Lúa Tại Tỉnh Vĩnh Long. Tạp chi Khoa học Truờng Đại học Cần Tho 2014, $35,79-86$.

9. Huy, H.T. Phân Tích Tác Động Của Khoa Học Kỹ Thuật Đến Hiệu Quả Sản Xuất Lúa Tại Cần Thơ và Sóc Trăng. Đề tài nghiên cứu khoa học cấp trường, Đại học Cần Thơ 2007, 8 , 47-56.

10. Duc Tran, D.; van Halsema, G.; Hellegers, P.J.G.J.; Phi Hoang, L.; Quang Tran, T.; Kummu, M.; Ludwig, F. Assessing Impacts of Dike Construction on the Flood Dynamics of the Mekong Delta. Hydrol. Earth Syst. Sci. 2018, 22, 1875-1896. https://doi.org/10.5194/hess-22-1875-2018.

11. Pham, C.H. Planning and Implementation of the Dyke Systems in the Mekong Delta, Vietnam. Dissertation, Bonn University: Germany, 2011.

12. Nguyen, H.T.L.; Nguyen, T.G. Surface Water Quality in Canals in An Giang Province, Viet Nam, from 2009 to 2016. J. Viet. Env. 2018, 10, 113-119.

13. Anh, B.L.; Tín, H.Q.; Điền, H.N. Xác Định Các Yếu Tố Ảnh Hưởng Đến Tiềm Năng Phát Triển Giống AG-Nếp Tỉnh An Giang. Tạp chi Khoa học Truờng Đại học Cần Tho 2017, $35-43$.

14. Tổng cục Môi trường Việt Nam. Quy Chuẩn Kỹ Thuật Quốc Gia về Nước Mặt QCVN 08MT:2015/BTNMT Available online: http://vea.gov.vn/quy-chuan (accessed on 6 April 2021). 


\title{
Assessment of the surface water quality and effectiveness of triple-glutinous rice cropping system in the full-dike protected area of Bac Vam Nao, An Giang province
}

\author{
Huynh Vuong Thu Minh ${ }^{*}$, Nguyen Thanh Tam $^{2}$, Dai Thi Huynh Nhu ${ }^{1}$, Nguyen \\ Truong Thanh ${ }^{1}$, Tran Van $\mathbf{T y}^{3}$ \\ ${ }^{1}$ College of Environment and Natural Resources, Can Tho University; \\ hvtminh@ctu.edu.vn; ntthanh@ctu.edu.vn \\ ${ }^{2}$ Mekong Delta Development Research Institute, Can Tho University; ngttam@ctu.edu.vn \\ ${ }^{3}$ College of Technology, Can Tho University; tvty@ctu.edu.vn
}

\begin{abstract}
Assessment of the surface water quality and the effectiveness of the tripleglutinous rice cropping system was conducted in the full-dike protected area in Bac Vam Nao (BVN protected area), An Giang province. The parameters of surface water quality was collected from the Department of Environment and Natural Resources (DONRes), including, $\mathrm{pH}$, Dissolved Oxygen (DO), Total Suspended Solids (TSS), Biological Oxygen Demand $\left(\mathrm{BOD}_{5}\right)$, Chemical Oxygen Demand (COD), nitrate $\left(\mathrm{NO}_{3}{ }^{-}\right)$, and phosphate $\left(\mathrm{PO}_{4}{ }^{3-}\right)$, for the period of 2010-2020. In-Situ method was used to measure the following parameters: $\mathrm{pH}$, TDS, EC, and DO at 20 locations in the Autumn-Winter cropping season of 2020. The effectiveness of the triple-glutinous rice cropping system in the BVN was assessed through farmer interviews. The results show that the mean values of $\mathrm{BOD}_{5}$ and $\mathrm{COD}$ inside the BVN were higher than those in the main rivers at $1 \%$ significance level. However, the impact of rice intensification inside BVN on water quality changes in the main rivers has not been found. The water quality at the beginning of the Autumn-Winter crop was better than that in the middle of the crop at $1 \%$ significance level. Glutinous rice intensification can bring higher profits; however, the profitability is greatly affected by yield, selling price and investment costs. In recent years, the productivity of glutinous rice has decreased, the profits are lower and the surface water quality pollution is also more than before.
\end{abstract}

Keywords: Surface water quality; Rice productivity; Profit; Full-dike protected area; Phu Tan. 